\title{
Hegemoni Dibalik Hubungan Bilateral Tiongkok-Indonesia
}

\author{
Rissa Amanda ${ }^{1^{*}}$ \\ ${ }^{1}$ Program Pasca Sarjana Komunikasi Fakultas IImu Sosial dan IImu Politik \\ Universitas Indonesia \\ Kampus UI Salemba 16424 Jakarta \\ *Email: rissa.airuisha@gmail.com
}

Naskah diterima 11 Desember 2020, Revisi 15 Maret 2021, Terbit 29 April 2021

\begin{abstract}
DOI: doi.org/10.21107/pamator.v14i1.9004
Abstract

China is the largest superpower country in Asia nowadays. With its popularity in the fields of technology, transportation, infrastructure and others has attracted ASEAN countries, including Indonesia, to become more interested in tightening cooperation with China. However, what is almost forgotten is how China takes advantage of this moment to expand its expansion to other countries and it starts from the nearest countries. In this study, the authors used qualitative research methods - descriptive analytic with Library Research data collection techniques. The purpose of this study is to see how hegemony in bilateral relations between Indonesia and China. The results are hegemonic practices exist in bilateral relations between Indonesia and China through the OBOR project and Mandarin Language Center institutions such as Confucius Institute
\end{abstract}

Key words: China, expansion, hegemony, bilateral relations

\section{PENDAHULUAN}

Perkembangan teknologi dan globalisasi masa kini telah memperketat standar kehidupan masyarakat Indonesia yang menuntut mereka agar lebih 'melek' terhadap kemajuan dunia dan lebih sadar akan daya bersaing yang semakin tinggi di seluruh aspek kehidupan. Keadaan seperti ini dapat dilihat dari terbukanya negara Indonesia terhadap negara asing, sehingga banyak dari mereka yang tertarik untuk menanamkan modalnya di Indonesia dan juga banyaknya tawaran pertukaran pelajar di institusi pendidikan. Dalam setiap kerjasama antar negara, tentunya dari setiap negara tersebut memiliki agenda dan keperluannya masing-masing. Keterbukaan ini justru menjadi peluang bagi negara asing untuk dapat memanfaatkan Indonesia sebagai salah satu negara berkembang yang memiliki kekayaan alam yang besar. Karena kemampuan pengelolaan kekayaan alam yang kurang baik dan memadai, celah ini pun dimanfaatkan oleh pihak asing. Selain itu, melihat sifat orang Indonesia yang identik dengan 'legowo', maka membuat pihak asing semakin tertarik untuk masuk dan bahkan juga mempengaruhi Indonesia.

Negara Tiongkok menjadi salah satu negara yang menjalin hubungan bilateral dengan Indonesia. Tiongkok yang terkenal dengan sebutan 'Negeri Tirai Bambu' tersebut merupakan negara yang memiliki tingkat perekonomian yang sangat baik, juga perkembangan teknologinya yang lebih cepat dibandingkan negara yang lain, sehingga Tiongkok dilihat sebagai negara adikuasa di Asia, bahkan sekarang ketenarannya sebagai negara adikuasa semakin meluas sampai ke negara Amerika Serikat dan Eropa. Tiongkok mampu memanjakan orang-orang di berbagai belahan dunia dengan produknya yang terbilang cukup murah, namun kualitas tidak kalah dengan produk berharga mahal lainnya. Bahkan mereka tidak mampu untuk menolak kehadiran barang-barang buatan Tiongkok tersebut.

Tahun ini, selepas memperingati 70 tahun jalinan hubungan bilateral antara Tiongkok dengan Indonesia yang sudah terbentuk sejak 13 April 1950, mengingatkan kita bahwa begitu eratnya hubungan kedua negara tersebut yang diawali dengan kerja sama di bidang kebudayaan dan pendidikan, di mana Tiongkok memberikan banyak beasiswa untuk pemuda-pemuda Indonesia agar dapat bersekolah langsung di Tiongkok, meskipun hubungan keduanya sempat terputus di tahun 1967-1989 sebagai dampak dari rezim Soeharto yang saat itu 
sedang berurusan dengan G30S/PKI, namun hubungan keduanya kembali membaik pada sekitar tahun 1990 (Firdaus, 2020). Kini, di masa kepemimpinan Joko Widodo sebagai presiden Indonesia dan Xi Jinping sebagai presiden Tiongkok, hubungan bilateral kian menghangat. Terbukti dengan adanya kerjasama antara negara Indonesia dengan negara Tiongkok, maka kita dapat melihat bagaimana akhirnya Tiongkok berhasil memasuki banyak sektor bidang di Indonesia, seperti pendidikan, ekonomi, proyek pembangunan infrastruktur, industri, dan maritim.

Semakin banyak orang Tiongkok yang masuk ke Indonesia, membuat masyarakat Indonesia dituntut untuk memiliki kemampuan bahasa asing tambahan selain bahasa Inggris, yaitu bahasa Mandarin. Kemampuan bahasa Mandarin pribumi ini yang akan dimanfaatkan untuk menjadi alat komunikasi langsung dengan orang Tiongkok yang minim berbahasa Inggris. Terutama di area perusahaan yang sekarang banyak diisi oleh orang-orang Tiongkok, termasuk atasannya.

Kebutuhan akan sumber daya manusia yang mampu berbahasa Mandarin menjadi meningkat di Indonesia. Di samping itu, perusahan-perusahaan Tiongkok yang ada di Indonesia pun bahkan sampai membuat program pelatihan bahasa Mandarin khusus di perusahaannya bagi pegawai pribumi yang belum bisa berbicara bahasa Mandarin. Selain itu, kebanyakan proyek pembangunan infrastruktur Indonesia yang dipegang langsung oleh Tiongkok, biasanya akan melibatkan banyak pekerja atau buruh asli dari Tiongkok yang tentunya berkolaborasi dengan buruh pribumi asal Indonesia dan mereka pun lagi-lagi diharuskan untuk mampu berbahasa Mandarin, meski paling minimal hanya dalam tahap percakapan sehari-hari saja.

Namun, ternyata tidak hanya sampai disitu, dewasa ini institusi pendidikan mulai dari SD hingga SMA dimasuki oleh kurikulum bahasa Mandarin, bahkan di jenjang perguruan tinggi pun ada. Maka kebutuhan guru bahasa Mandarin pun juga ikut meningkat. Banyak tempat kursus lokal maupun lembaga bahasa yang mewakili langsung negara Tiongkok berbondongbondong untuk menawarkan layanan kursus bahasa Mandarin dengan harga yang relatif terjangkau. Selain itu, lembaga-lembaga tersebut banyak menawarkan beasiswa belajar bahasa Mandarin langsung di Tiongkok selama beberapa waktu.

Dalam penelitian ini, penulis memilih acuan perspektif teori hegemoni untuk melakukan penelitian. Jika membicarakan teori hegemoni, maka konsep yang seringkali terdengar adalah konsep hegemoni yang digagas oleh Antonio Gramsci, seorang filsuf asal Italia yang terkenal dengan idenya mengenai hegemoni. Hegemoni bagi Gramsci adalah proses reproduksi makna dan praktik kelompok dominan kepada kelompok subordinat dan seluruh lapisan masyarakat dengan menghadirkan satu tujuan dan kepentingan tertentu kelompok dominan dan dominasi yang dilakukan lebih kepada negosiasi antar kelompok untuk saling bekerja sama dalam satu tujuan yang sama (Turner, 2003; Barker, 2004).

Kepentingan tertentu kelompok tersebut biasanya berhubungan dengan kapitalisme dan ada unsur ideologi di dalamnya. Kemudian ideologi ini yang akan dijadikan sebagai alat pendukung hegemoni kelompok-kelompok dominan yang berkuasa tersebut, sehingga kekuasaan mereka akan tetap langgeng. Di samping itu, teori yang digagas oleh Gramsci ini merupakan bentuk pengkritikan atas teori hegemoni pendahulunya, Karl Marx, yang cenderung menekankan satu wacana determinisme kelas dan ekonomi oleh kelompok dominan (Ali, 2017).

Pada dasarnya, hegemoni terjadi di dalam strukturasi hubungan sosial masyarakat. Selama proses negosiasi di antara kelompok dapat berhasil dan juga dapat menciptaan kesadaran palsu, maka hegemoni tersebut dapat dikatakan berjalan dengan lancar. Kemudian di dalam hegemoni itu sendiri terdapat aktor-aktor yang memiliki fungsinya masing-masing. Aktor-aktor tersebut adalah kelompok kaum intelektual yang sudah disaring. Jadi tidak semua kaum intelektual dapat memasuki sistem hegemoni tersebut. Lalu kelompok kaum intelektual yang terpilih bertanggung jawab untuk mengelola kehidupan masyarakat dan biasanya terdapat beberapa golongan kaum intelektual yang justru memanfaatkan momen ini untuk membuat perlawanan terhadap hegemoni (Mosco, 2009; Storey, 2015). 


\section{METODOLOGI}

Pada penelitian kajian budaya ini, penulis menggunakan paradigma kritis dengan metode penelitian kualitatif jenis deskriptif analitik dan teknik pengumpulan data melalui Library Research, yaitu dengan mengumpulkan data dari berbagai sumber buku, jurnal ilmiah, dan juga situs resmi yang berkaitan dengan topik penulis. Kemudian data-data yang penulis dapatkan akan digunakan sebagai sumber untuk menghasilkan sebuat penelitian.

\section{HASIL PEMBAHASAN}

Tiongkok yang terkenal dengan keunggulannya dalam bidang ekonomi, teknologi, maupun infrastruktur, membuatnya dilihat sebagai negara super power yang serba bisa. Bahkan keunggulan Tiongkok menempati banyak wilayah di dunia ini. Nyatanya, ketika kita melihat suatu produk barang, kebanyakan dari barang tersebut pasti memiliki tagline 'Made in China'. Hal ini membuktikan bahwa Tiongkok sudah merajalela dimana-mana dan kita tidak mampu mengendalikannya, kecuali jika Indonesia menutup kerja sama dengan Tiongkok dan tidak memperbolehkan Tiongkok masuk ke Indonesia. Tahun ini Indonesia dan Tiongkok telah merayakan peringatan 70 tahun kelanggengan hubungan kerja sama kedua negara tersebut pada bulan April lalu. Menurut rekam jejak yang ada, kerja sama berawal dari sektor kebudayaan dan pendidikan, kemudian sekarang sektor-sektor lainnya juga banyak dimasuki oleh Tiongkok. Kerja sama ini tidak serta-merta tanpa tujuan. Namun ada agenda tertentu di dalamnya.

Sebagai contoh, proyek terbesar Tiongkok yang sedang marak saat ini adalah proyek OBOR atau yang disebut juga dengan One Belt One Road. Proyek ini dimunculkan oleh Presiden Xi Jinping sejak akhir tahun 2013, di mana proyek ini difokuskan pada pembangunan jalur lalu lintas perdagangan darat dan laut, yang melintasi benua Asia, Eropa, dan Afrika (Harahap, 2020). Selain itu, proyek Tiongkok ini juga bertujuan untuk meningkatkan dan memperkuat jaringan koneksi dengan negara-negara ASEAN, baik dalam bidang keuangan, pembangunan infrastruktur dan transportasi, serta bisnis industri. Dengan kata lain, Tiongkok ingin memperluas wilayah eskpansinya mulai dari negara-negara terdekatnya.

Sejalan dengan hal tersebut, pada tahun 2015 Presiden Joko Widodo juga memiliki agenda di mana beliau ingin menjadikan Indonesia sebagai negara 'poros maritim di dunia' dan ingin memberantas tindakan kriminal illegal fishing yang dilakukan oleh pihak asing. Sehingga akhirnya Tiongkok memanfaatkan momen ini dan kembali bekerja sama dengan Indonesia di dalam urusan maritim. Tiongkok berperan sebagai pihak supplier yang menjual persenjataan militer dan alat-alat kebutuhan maritim lainnya untuk keperluan keamanan laut (Tao et al., 2020).

Oleh karena itu, melihat perkembangan dunia yang semakin maju, Presiden Joko Widodo mulai memfokuskan pembangunan negara Indonesia di sektor yang masih kurang memadai, yaitu sektor transportasi sebagai yang paling utama, agar daerah satu dengan daerah lainnya dapat lebih terhubung dengan mudah, misalnya saja proyek kereta api cepat Jakarta-Bandung, Namun, untuk dapat mengimplementasikan hal tersebut, Indonesia tentu memerlukan biaya yang tidak sedikit. Sehingga beliau menyiasatinya dengan melakukan kerjasama dengan Tiongkok, guna mendapatkan bantuan pinjaman dari 'Negeri Tirai Bambu' tersebut. Tiongkok pun dengan senang hati melakukannya. Oleh karena itu, sebagai bentuk rasa terima kasih, Presiden Joko Widodo memberikan banyak kesempatan pada Tiongkok untuk dapat terlibat dalam banyak proyek pembangunan di Indonesia, termasuk proyek kereta api cepat JakartaBandung. Proyek ini merupakan proyek konsorsium oleh PT Kereta Cepat Indonesia Cina (KCIC), PT Wijaya Karya, PT Kereta Api Indonesia, PT Jasa Marga, PT Perkebunan Nusantara, dan China Railway (Wijaya, 2020).

Kerja sama yang dilakukan Indonesia dengan Tiongkok lebih cenderung kepada kerja sama antar BUMN. Jika dilihat lebih jauh, sebenarnya dalam hal ini Tiongkok sudah mendapatkan hati Indonesia dan ia perlahan mencoba untuk lebih dalam lagi memasuki lapisan esensial Indonesia, di mana lapisan tersebut merupakan sektor utama yang membutuhkan banyak perbaikan dan bantuan dari eksternal untuk dapat memperbaikinya. Tentu saja, Tiongkok yang 
berkedok 'dermawan' menawarkan diri untuk membantu memperbaiki sektor tersebut.

Contoh lainnya adalah bidang pendidikan. Dapat dilihat bahwa kerja sama yang terjalin adalah dalam bentuk pemberian beasiswa kepada para pemuda Indonesia agar dapat bersekolah langsung di Tiongkok. Ketika kerja sama dengan Tiongkok semakin terbuka, banyak perusahaan Tiongkok mulai menempati beberapa wilayah di Indonesia dan pegawainya pun merupakan orang asli dari Tiongkok. Rata-rata dari mereka kurang fasih bahkan tidak bisa berbicara bahasa Inggris sama sekali, apalagi bahasa Indonesia. Oleh karena itu, mereka mulai membutuhkan tenaga penerjemah bahasa Mandarin dari Indonesia. Kemudian disusul dengan pendirian lembaga bahasa Mandarin ternama asal Tiongkok bernama Confusius Institute $(\mathrm{Cl})$ atau yang dikenal dengan nama Pusat Bahasa Mandarin (PBM) yang berdiri pertama kalinya di Indonesia pada tahun 2007 sebagai lembaga terpercaya yang memberikan fasilitas kursus bahasa Mandarin langsung dari native speaker Tiongkok dan ditujukan untuk para pemula dari tingkat SD hingga mahasiswa, juga untuk pegawai pemerintah sampai masyarakat umum (Ansori, 2017).

Confusius Institute $(\mathrm{Cl})$ ini merupakan lembaga bahasa Mandarin resmi dari Beijing dibawah HANBAN, kantor perwakilan program bahasa Mandarin Internasional Kementrian Pendidikan Tiongkok, di mana lembaga ini didanai dan diorganisir langsung oleh pemerintah Tiongkok. $\mathrm{Cl}$ sebenarnya sudah hadir di beberapa negara, termasuk Amerika Serikat dan penempatannya berada di dalam universitas-universitas, temasuk di Indonesia. Biasanya, jika ingin membangun $\mathrm{Cl}$, pihak Tiongkok hanya bertugas menyalurkan guru-guru native speaker Mandarin yang berkualitas, kemudian Tiongkok memberikan persyaratan agar negara tempat $\mathrm{Cl}$ akan dibangun menyiapkan lahan dan fasilitas yang memadai.

Dalam kacamata kritis, kehadiran $\mathrm{Cl}$ di Indonesia bukan tanpa alasan. la menjadi agen yang dikirim oleh negara Tiongkok sebagai perwakilan untuk menyebarluaskan kebudayaan dan bahasa Mandarin agar orang-orang Indonesia dapat memahami Tiongkok. Dengan begitu, diharapkan komunikasi antara Indonesia dengan
Tiongkok dapat berjalan dengan lancar. Di samping itu, $\mathrm{Cl}$ ini dicurigai sebagai kendaraan propagranda Tiongkok terhadap negara-negara yang terlibat dalam kerja sama pengadaan lembaga bahasa Mandarin (Theo \& Leung, 2018). Selain itu, secara tidak langsung orang-orang yang mengenyam pendidikan bahasa Mandarin dipersiapkan untuk menjadi agen-agen perwakilan penerjemah Mandarin bagi orang-orang Tiongkok yang ada di Indonesia dan dipekerjakan di perusahaan-perusahaan Tiongkok.

Berdasarkan rangkaian contoh di atas, jika kita ingin mengaitkannya dengan konsep hegemoni Gramsci, tentu dapat dilihat dari adanya kekuasaan kelompok dominan yang memiliki tujuan tertentu dalam kerja sama yang terjalin antara Indonesia dengan Tiongkok. Negeri Tirai Bambu ini adalah bagian dari kelompok dominan, karena posisinya di Asia termasuk negara yang paling berkuasa saat ini. Kemudian langkah yang dilakukan Tiongkok selanjutnya adalah mempromosikan proyek OBOR kepada negara-negara tetangga, termasuk Indonesia. Sebagai bentuk negosiasi, Tiongkok menawarkan ini sebagai proyek yang dapat menguntungkan bersama. Tiongkok mampu memasuki celah-celah negara yang sedang membutuhkan bantuan tertentu dan berperan sebagai penyedia fasilitas untuk mempermudah atau bahkan menjadi solusi bagi negara-negara yang sedang dalam kegalauan tersebut.

Salah satunya adalah Indonesia yang sedang memiliki masalah dalam hal keamanan maritim dan pembangunan transportasi. Tiongkok membantu Indonesia dalam bentuk peminjaman dana sekaligus penyedia barang-barang kebutuhan industri, infrastruktur, maupun maritim yang harga produknya cukup terjangkau. Selain itu, biaya bea cukainya pun tidak begitu mahal.

Tanpa disadari, dengan banyaknya bantuan yang ditawarkan oleh Tiongkok, membuat Indonesia menjadi ketergantungan pada Tiongkok. Sebenarnya itulah yang diinginkan olehnya. Ketergantungan membuat Indonesia tidak bisa lepas dari Tiongkok, apalagi jika masih ada hutang Indonesia yang belum dikembalikan kepada Tiongkok, seolah-olah Indonesia terus berputar di lingkaran yang sama. Tiongkok berhasil menggenggam Indonesia di 
tangannya, karena ia pun berhasil menciptakan kesadaran palsu untuk Indonesia, yaitu menganggap Tiongkok sangat baik karena ia sudah berbesar hati untuk membantu Indonesia. Ditambah lagi, sekarang Indonesia justru memberikan peluang keterbukaan yang lebih besar kepada Tiongkok.

Selanjutnya dalam hal ini, orang-orang Tiongkok semakin banyak yang masuk ke Indonesia dan itu berarti Indonesia harus mempersiapkan wakil-wakilnya yang dapat berbahasa Mandarin agar bisa menjembatani komunikasi di antara Indonesia dengan Tiongkok. Tidak menutup kemungkinan bahwa orang-orang yang dikirim langsung dari Tiongkok ke Indonesia, termasuk para tenaga pengajar Mandarin native speaker, merupakan kaum-kaum intelektual yang bertugas untuk membentuk kesadaran palsu itu dengan menanamkan nilai-nilai 'keTiongkok-an' kepada masyarakat Indonesia.

Nilai-nilai 'ke-Tiongkok-an' tersebut bisa kita lihat di perusahaan-perusahaan Tiongkok yang mempekerjakan orang pribumi. Mereka biasanya akan menunjukkan pada pekerja Indonesia, bahwa bekerja dalam sistem Tiongkok harus mengikuti peraturan-peraturan, seperti menghormati orang yang lebih tua atau memiliki jabatan yang lebih tinggi, lalu bertahan di tengah tekanan yang berat, menjunjung tinggi ketepatan waktu (waktu adalah uang), tidak malas bekerja, dan harus selalu berorientasi pada profit. Bahkan tiap pegawai pun harus siap lembur hingga larut malam, maupun bekerja pada hari sabtu dan minggu tanpa mendapatnya uang lembur. Hal ini menjadi pola tersendiri bagi pegawai pribumi yang sudah terbiasa bekerja dengan orang Tiongkok. Mereka akan menganggap hal ini adalah hal yang lumrah karena sifat orang Tiongkok yang seperti itu. Sehingga mereka akan terus mencari pembelaan, padahal sebenarnya sebagai orang yang berada di negaranya sendiri dan juga sebagai seorang manusia, tentunya punya hak untuk berpendapat. Padahal, mereka sedang di bawah pengaruh strukturasi Tiongkok, di mana orang-orang tidak akan mampu bergerak begitu masuk ke dalam sistem Tiongkok.

Sementara, pada bidang pendidikan bahasa Mandarin yang digawangi oleh $\mathrm{Cl}$, yaitu lembaga bahasa Mandarin yang memiliki cabang di beberapa universitas di Indonesia, akan membantu masyarakat pribumi yang ingin belajar bahasa Mandarin langsung dengan native speaker. Mengingat kebutuhan bahasa Mandarin semakin meningkat, sejalan dengan banyaknya kehadiran orang-orang Tiongkok saat ini. Artinya, kelompok kaum-kaum intelektual ini saling melengkapi dan punya fungsinya masing-masing di masyarakat, namun tetap pada satu tujuan yang sama, yaitu menguasai Indonesia. Para pengajar native speaker Mandarin bertugas untuk membuat kurikulum pengajaran bahasa Mandarin yang baik dan benar, sekaligus mengajari orangorang bahasa Mandarin termasuk mencetak guru-guru bahasa Mandarin pribumi, serta menyebarkan misi budaya di mana mereka memperkenalkan bentuk-bentuk budaya Tiongkok yang cukup menarik, seperti kaligrafi, wushu, dan sebagainnya.

Memang masyarakat Indonesia perlu belajar bahasa Mandarin karena saat ini dan mungkin ke depannya akan ada banyak yang membutuhkan penerjemah bahasa Mandarin dan bisa mendapat bayaran yang tinggi asalkan penerjemah Mandarin tersebut fasih. Lagi-lagi masyarakat Indonesia dibawah strukturasi kelompok dominan, ada tawaran dan negosiasi yang dilakukan Tiongkok. Banyak dari masyarakat Indonesia yang berlomba-lomba untuk belajar bahasa Mandarin seolah-olah itu kebutuhan mereka dan bahasa Mandarin juga mulai disalurkan melalui institusi pendidikan lainnya di Indonesia, bahkan mulai dari jenjang sekolah dasar hingga perguruan tinggi. Nampaknya Tiongkok siap mencetak orang Indonesia menjadi bawahannya dengan cara halus, yaitu penanaman ideologi Tiongkok melalui jalur internal negara (lembaga-lembaga) dan banyak dari kita yang tidak sadar akan strategi tersebut.

Jika kita melihat lebih dalam, seharusnya masyarakat Indonesia bisa mengkritisi hal ini, karena orang-orang Tiongkok berada di wilayah negara Indonesia, jadi mereka pun harus belajar bahasa Indonesia juga. Apalagi mereka menanamkan modalnya di Indonesia dan tentunya akan mengelola atau bahkan tinggal di Indonesia dalam jangka waktu yang lama. Sementara, apabila kita ingin pergi ke Tiongkok, paling minimal harus dapat berbicara bahasa Mandarin terlebih dahulu karena minimnya orang-orang yang dapat 
berkomunikasi dengan bahasa Inggris di sana.

Berdasarkan semua hal ini, akhirnya dapat terlihat bahwa terdapat hegemoni dibalik segala tindakan Tiongkok berkedok 'kerja sama bilateral' terhadap Indonesia, dan mungkin juga berlaku bagi negara-negara lainnya. Apalagi ambisi dan semangat Tiongkok untuk menjadi negara adidaya juga bisa menjadi gejala utama dalam hegemoni. Agen-agen intelektual perwakilan Tiongkok yang dikirim ke Indonesia adalah agen terpilih untuk menjalankan misi negara. Mereka menjalankan misi melalui penanaman ideologi di lembaga-lembaga institusi untuk dapat mereproduksi praktikpraktik hegemoni yang dapat melanggengkan kekuasaan Tiongkok.

\section{KESIMPULAN}

Kesimpulan dari studi ini adalah bahwa negara Tiongkok akan terus melancarkan dan memperluas praktik hegemoninya dalam bentuk apapun baik kepada Indonesia maupun negara lainnya, tergantung dari kebutuhan. Namun yang harus diwaspadai adalah praktik atau strategi hegemoninya yang seperti bunglon. Jadi, yang terpenting bagi Indonesia adalah harus bisa lebih sadar dan kritis terhadap setiap tindakan negara Tiongkok dan harus lebih berhati-hati agar tidak berputar terus di lingkaran yang sama, serta jangan mudah tergiur. Semangat Tiongkok untuk menjadi negara yang independen dan lebih baik dapat ditiru, namun untuk hal lain harus dipikirkan terlebih dahulu, apakah sesuai dengan ideologi Indonesia atau tidak.

\section{DAFTAR PUSTAKA}

Ali, Z. Z. (2017). Pemikiran Hegemoni Antonio Gramsci (1891-1937) Di Italia. Jurnal Yaqzhan: Analisis Filsafat, Agama dan Kemanusiaan, Vol. 3(2), 6381. doi: 10.24235/jy.v3i2.5482

Ansori, F. (2017). Pusat Bahasa Mandarin Universitas Al Azhar Indonesia: Refleksi dan Proyeksi Hubungan Sosial Budaya China-Indonesia. Jurnal Al-Azhar Indonesia Seri Humaniora, Vol. 4(1), 1116. doi:10.36722/sh.v4i1.246
Barker, Chris. (2004). Cultural Studies: Teori \& Praktik (Nurhadi, Penerjemah.). Yogyakarta: Kreasi Wacana.

Harahap, F., \& Susiatiningsih, R. H. (2020). Analisis Potensial Tiongkok Untuk Menjadi Negara Hegemoni di Kawasan Asia Timur Melalui Strategi One Belt One Road. Journal of International Relations, Vol. 6(2), 164-172.

Mosco, Vincent. (2009). The Political Economy of Communication (2nd ed.). Los Angeles: Sage Publications.

Putri, S. Y., \& Ma'arif, D. (2019). Kerja Sama Ekonomi-Politik Indonesia dan Cina pada Implementasi Program Belt and Road Initiative. Jurnal Kajian Lemhannas RI, Vol. 7 (3), 53-66.

Storey, John. (2015). Cultural Theory and Popular Culture: An Introduction (7th ed.). London: Routledge.

Tao, L. W., Thamrin, S., \& Waluyo, S. D. (2020). Kerjasama Keamanan ChinaIndonesia Guna Menangkal Ancaman Keamanan Maritim Kedua Negara. Jurnal Strategi Pertahanan Laut, Vol. 5 (3), 51-68.

Theo, R., \& Leung, M. W. (2018). China's Confucius Institute in Indonesia: Mobility, frictions and Loca surprises. Journal Sustainability, Vol. 10(2), 530.

Thung, Ju Lan. (2017). Confucius Institute at Universitas Al Azhar, Jakarta: The Unseen Power of China. Jurnal Wacana, Vol. 18 (1), 148-182.

Wijaya, H. (2020). Aktualisasi Kebijakan China One Belt and One Road Di Indonesia Melalui Pembangunan Kereta Cepat Jakarta-Bandung. Jurnal Dinamika Global, Vol. 5(1), 109-122. 
Ariyadi, M. Y. (2019). Analisis pengaruh GDP riil, kurs dan harga udang terhadap volume ekspor udang di Indonesia menurut negara tujuan tahun 2011-2017 [UPN "Veteran" Yogyakarta]. In PhD Thesis.

https://doi.org/10.1017/CBO97811074153 24.004

Carolina, L. T., \& Aminata, J. (2019). Analisis daya saing dan faktor yang mempengaruhi ekspor batu bara. Diponegoro Journal of Economics, 1(1), 9-21.

Chandra, D., Ismono, R. H. dan, \& Kasymir, E. (2013). Prospek perdagangan kopi robusta Indonesia di pasar internasional. Jurnal IImu IImu Agribisnis, 1(1), 10-15.

Ginting, C. P., \& Kartiasih, F. (2019). Analisis ekspor kopi Indonesia ke negara- negara ASEAN. Jurnal Ilmiah Ekonomi Dan Bisnis, 16(2), 143-157. https://doi.org/10.31849/jieb.v16i2.2922

Gujarati, D. N., \& Porter, D. C. (2010). Basic Econometrica (5th ed.). Mc Graw Hill.

Komalasari, A. (2008). Analisis tentang pelaksanaan plant layout dalam usaha meningkatkan efisiensi produksi. Universitas Widyatama.

Krugman, P., \& Obstfeld, M. (2003). International Economics: Theory and Policy (Sixth Ed). Elm Street Publishing Services,

Inc. https://doi.org/10.4324/9780203462041

Mankiw, N. G. (2016). Principles of economics (8th ed.). Cengage Learning.

Marbun, L. (2015). Pengaruh produksi, kurs, dan gross domestic product (GDP) terhadap ekspor kayu lapis. Economics Development Analysis Journal, 4(2), 129136.

https://doi.org/10.15294/edaj.v4i2.14812

Nanda, Z. (2019). Analisis pengaruh PDB Indonesia, harga kopi dunia, dan nilai tukar USD - rupiah terhadap volume ekspor kopi Indonesia tahun 1985 - 2017. In Skripsi. Universitas Islam Negeri Syarif Hidayatullah.

Nopirin. (1999). Ekonomi internasional (3rd ed.). BPFE.

Simanjuntak, P. T. H., Arifin, Z., \& Mawardi, M. K. (2017). Pengaruh produksi, harga internasional dan nilai tukar rupiah terhadap volume ekspor rumput laut Indonesia (studi pada tahun 2009 - 2014). Journal of Business Administration, 50(3), 163-171.

administrasibisnis.studentjournal.ub.ac.id

Sinta, N. M., Alamsyah, Z., \& Elwamendri. (2017). Analisis daya saing ekspor kopi Indonesia dan Vietnam di pasar ASEAN. Jurnal Ilmiah Sosio Ekonomika Bisnis, 20(1), 1-11.

Soekartawi. (2005). Agribisnis: Teori dan aplikasinya (8th ed.). Raja Grafindo Persada.

Sukirno, S. (2015). Makroekonomi: Teori pengantar (3rd ed.). RajaGrafindo Persada. 